\title{
EFFECTS OF CHANGE IN BODY POSTURE ON PLASMA AND SERUM ELECTROLYTES IN NORMAL SUBJECTS AND IN PRIMARY ALDOSTERONISM
}

\author{
S. SONKODI, M. G. NICHOLLS, A. M. M. CUMMING AND J. I. S. \\ ROBERTSON
}

First Department of Medicine, Szeged University Medical School, Szeged, Hungary, Hypertension Section, University of Michigan Medical School, Ann Arbor, Michigan, USA and MRC Blood Pressure Unit, Western Infirmary, Glasgow, UK

(Receiced 7 May 1980; revised /I December 1980; accepted 22 December 1980)

\begin{abstract}
SUMMARY
We observed that change in body posture from the supine to the erect position in normal volunteers was associated with a rise in circulating potassium and a fall in sodium concentrations, irrespective of whether the electrolytes were measured in serum or plasma, or whether head-up tilt or ambulation was used. In patients with primary aldosteronism, the fall in serum sodium and rise in serum potassium with ambulation tended to obscure the characteristic electrolyte abnormalities of that syndrome. These changes in potassium and sodium could contribute to the rise in aldosterone secretion on orthostasis. The body posture of patients should be considered in the interpretation of plasma and serum electrolyte levels.
\end{abstract}

Abnormalities in circulating sodium and potassium concentration are vital clues in the diagnosis of many important clinical disorders. It is generally known that attention must be paid to the technique of venepuncture (Farber et al., 1951; Brown et al., 1970), in particular avoiding forearm muscular exercise, as well as to the subsequent processing of blood specimens (Brown et al., 1970; Danowski, 1941) if electrolyte measurements are to reflect accurately the circulating sodium and potassium concentrations. The effects of change in body posture on sodium and potassium levels are less well appreciated. We observed significant alterations in plasma and serum electrolyte concentrations in normal subjects on moving from the recumbent to the upright position. These posture-related electrolyte changes occurred also in patients with primary aldosteronism, and tended to obscure the characteristic electrolyte abnormalities of that syndrome. The rise in circulating potassium and fall in sodium could also contribute to the increase in aldosterone secretion with orthostasis.

Correspondence: Dr J. I. S. Robertson, MRC Blood Pressure Unit, Western Infirmary, Glasgow G I I 6NT. 0300-0664/81/0600-0613\$02.00 C 1981 Blackwell Scientific Publications 


\section{METHODS}

The experimental procedures were approved by the respective ethical supervisory committees of the Western Infirmary, Glasgow, the University of Michigan Medical School, and the Szeged University Medical School. All volunteers gave fully informed consent.

\section{Experimental Groups}

\section{a Head-up tilting}

Eight normal males aged 20-37 years lay horizontal on a tilting table for $1 \mathrm{~h}$; this was then tilted head-up to 85 for $2 \mathrm{~h}$, and finally returned to horizontal for $1 \mathrm{~h}$. Peripheral venous blood samples were withdrawn and plasma separated 15 and $5 \mathrm{~min}$ before tilting, after 1 and $2 \mathrm{~h}$ of tilting, and $1 \mathrm{~h}$ after return to the horizontal. All experiments started between 1300 and $1400 \mathrm{~h}$ after the subjects had taken a light lunch.

This study was carried out as part of a series of investigations involving later drug administration. However, regular changes in plasma electrolyte concentrations were noted, so additional and separate experiments were performed as follows.

\section{$b \quad$ Further studies of head-up tilting}

Nine volunteers aged 19-40 years, and including one female, underwent head-up tilting exactly as under $(a)$ above. Peripheral venous blood samples were drawn and plasma separated after 45 and 60 min supine; after 1 and $2 \mathrm{~h}$ of tilting; and finally $1 \mathrm{~h}$ after return to the horizontal. These experiments started between 0800 and $0900 \mathrm{~h}$ (six subjects) or 1300 and $1400 \mathrm{~h}$ (three subjects) after the volunteers had taken a light breakfast or lunch.

\section{c Head-up tilting with superior cena caral sampling}

With strict aseptic precautions, six males aged 23-31 years had a hollow needle $\left(\right.$ Medicut $\left.^{R}\right)$ inserted into an antecubital vein. A fine polythene catheter was then passed through the lumen until the tip lay in the superior vena cava. This inner catheter was kept patent by being flushed with heparinized $0.9 \%$ sodium chloride between sample taking. The experimental procedure in this group was otherwise exactly as in group $(b)$.

\section{d Ambulation in normals}

Twelve males aged 21-45 years were studied on three occasions: after 4 days of sodium-restricted diet (urinary sodium output on the fourth day $26.4 \pm 16$, mean \pm SD $\mathrm{mmol} / 24 \mathrm{~h}$ ), after 4 days of 'normal' sodium intake (final urinary sodium output $131 \cdot 8 \pm 28 \cdot 5 \mathrm{mmol} / 24 \mathrm{~h}$ ), and lastly after 4 days of high sodium intake (final urinary sodium output $246 \pm 49 \cdot 7 \mathrm{mmol} / 24 \mathrm{~h}$ ). Potassium intake was kept constant throughout (respective potassium excretion rates at the end of each dietary period $68 \cdot 3 \pm 18 \cdot 1$, $75 \cdot 5 \pm 32 \cdot 3$, and $78 \cdot 3 \pm 29 \cdot 6$, mean $\pm \mathrm{SD}, \mathrm{mmol} / 24 \mathrm{~h}$ ). Subjects attended the Clinical Research Center at the University of Michigan fasting at $0800 \mathrm{~h}$ after 4 full days of each dietary period, and peripheral venous samples were obtained and serum separated after 1 $\mathrm{h}$ of supine rest and again after $1 \mathrm{~h}$ of quiet walking.

\section{$e$ Ambulation in patienis with primary aldosterone excess}

Nine consecutive patients presenting at the University of Michigan Medical Center with primary aldosterone excess (six males, three females; aged 18-53 years) were studied. 
All had elevated plasma aldosterone concentration and aldosterone excretion rates, together with suppression of plasma renin activity. Six patients had a single adrenocortical adenoma demonstrated by adrenal scintiscanning and adrenal venography; all six adrenal venous plasma samples showed a higher concentration of aldosterone on the suspect than on the contralateral side. An adrenocortical adenoma was confirmed at operation in all five who came to surgery. In contrast, these tests indicated bilateral adrenocortical disease in the remaining three patients. All nine were studied, having received no medications for at least 2 weeks, first after 4 days of high sodium intake $(180 \mathrm{mmol} / 24 \mathrm{~h})$, and then again after 4 days of low sodium intake (10 $\mathrm{mmol} / 24 \mathrm{~h}$ ), potassium intake being kept constant throughout at $100 \mathrm{mmol} / 24 \mathrm{~h}$. Peripheral venous blood samples were obtained and serum separated after overnight recumbency and fasting at $0800 \mathrm{~h}$ and again after $2 \mathrm{~h}$ of quiet ambulation.

\section{$f$ Supine controls: plasma}

Twelve healthy male volunteers were studied, peripheral venous blood samples being taken for plasma assays at hourly intervals during $4 \mathrm{~h}$ of recumbency.

\section{$g$ Supine controls: serum}

In fourteen healthy male volunteers, peripheral venous blood samples were taken for serum assays at hourly intervals over $4 \mathrm{~h}$ of recumbency.

\section{Blood sampling, separation of plasma and serum, and assay}

Blood samples were withdrawn without the aid of tourniquets and avoiding forearm muscular exercise, employing either individual venepunctures for each specimen or an indwelling plastic or metal cannula kept patent between samples with heparinized $0.9 \%$ sodium chloride or $5 \%$ dextrose. Dead-space was well cleared before each blood collection. Samples for serum were taken into glass containers; for plasma into tubes containing lithium heparin. Care was taken to avoid red cell trauma when transferring blood into the containers and mixing with anticoagulant. In the initial tilt study $(a)$, blood samples were separated together at the end of the experiment by centrifugation at $4^{\circ} \mathrm{C}$ and the plasma stored frozen at $-20^{\circ} \mathrm{C}$. In all other studies plasma or serum was separated at room temperature within $15 \mathrm{~min}$ of withdrawal and either analysed within $2 \mathrm{~h}$ or stored at $4^{\circ} \mathrm{C}$ to await assay. Sodium and potassium concentrations were estimated by flame photometry. To check for possible haemolysis, in samples from six volunteers in experiment $(b)$, plasma obtained before and during tilting was subjected to spectroscopy for haemoglobin estimation.

\section{RESULTS}

Head-up tilting in normal volunteers was, in all studies $(a, b$ and $c$ ), associated with a significant rise in mean plasma potassium concentration (Table 1). Following return to the horizontal, values returned towards, but did not always achieve, pre-tilt levels. The most marked rise during tilting, and the clearest subsequent fall, was seen in the subjects in whom samples were withdrawn from the superior vena cava (group $c$ ).

Concomitant with the rise in plasma potassium, a significant fall in plasma sodium was seen in studies $(a)$ and $(b)$, in which samples were withdrawn from a superficial vein, with a 


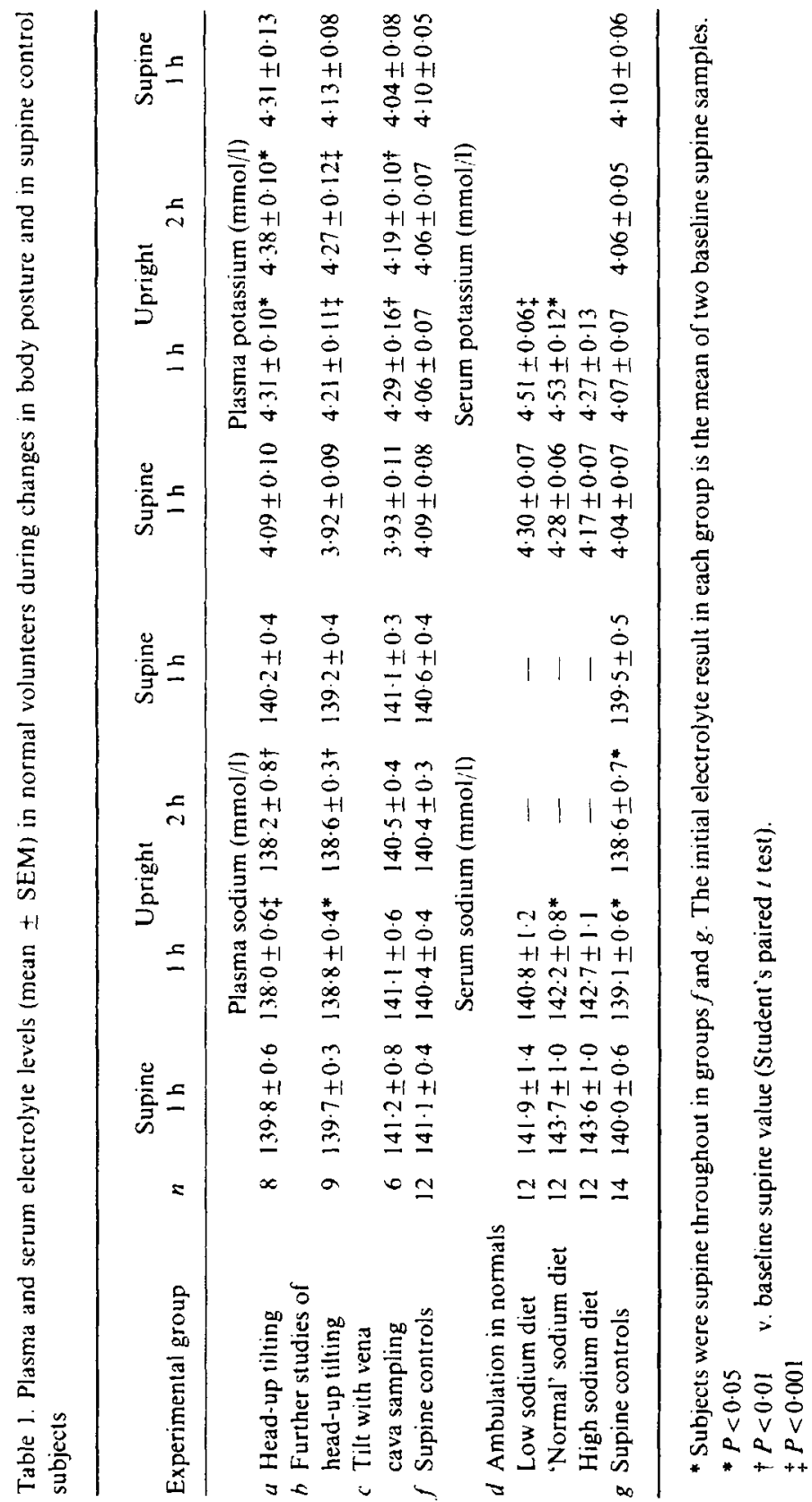




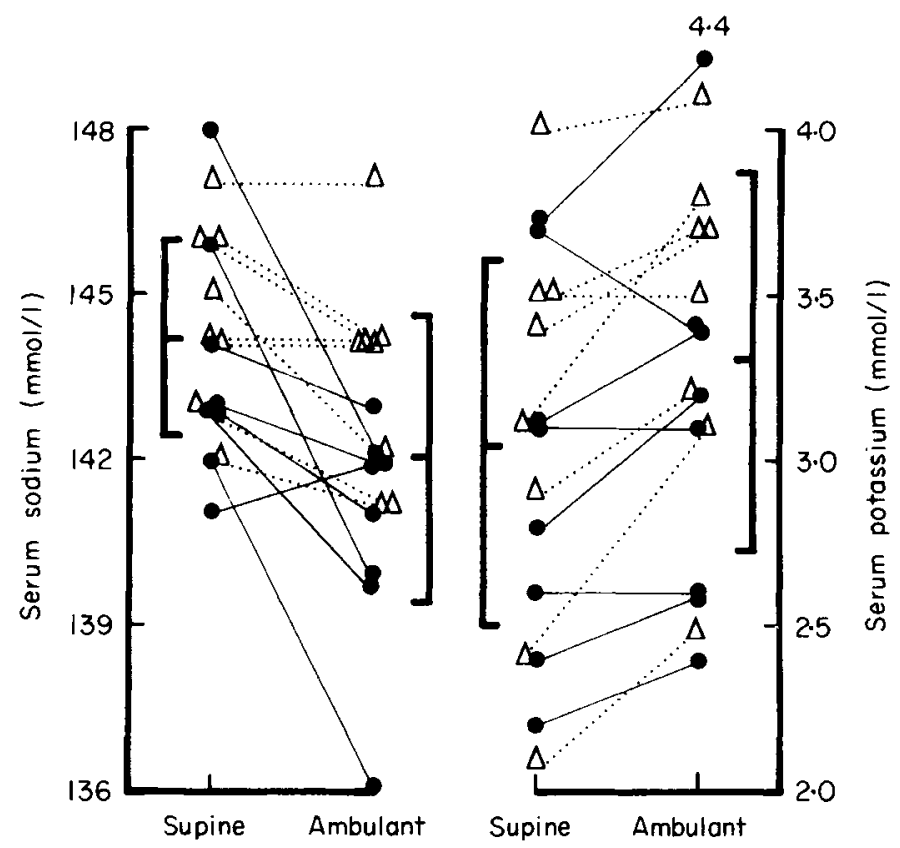

Fig. 1. Fasting overnight supine, and $1 \mathrm{~h}$ ambulatory serum sodium and potassium levels in nine patients with primary aldosteronism. Samples were obtained from all but one patient during a sodium-restricted diet $(\Delta \ldots . \Delta)$ and from eight of the nine patients after 4 days of a high salt intake $(\bullet \bullet)$. The mean and S.D. are indicated by the vertical bars.

return to values not significantly different from pre-tilt levels on re-assuming the horizontal position (Table 1). However, in experiment $(c)$, in which samples were withdrawn from the superior vena cava, no significant changes in plasma sodium were found.

Ambulation in normal subjects (group $d$ ) was similarly accompanied by a rise in serum potassium concentration, the changes being statistically significant when the subjects were taking normal and low sodium diets, but not when on the high salt regime (Table 1 ). Serum sodium fell during ambulation, but the magnitude of this change was similar to that seen at the same time interval in supine volunteers.

In patients with primary aldosterone excess (group $e$ ), ambulation for $2 \mathrm{~h}$ was accompanied by a highly significant fall in serum sodium (paired $t=3.83, P<0.005$ ) and rise in serum potassium (paired $t=3.75, P<0.005$; Fig. 1). The changes were similar in patients with and without adrenocortical adenoma. However the magnitude of the serum sodium changes was greater on the high salt diet $(143 \cdot 75 \pm 2 \cdot 25$ supine, $140 \cdot 75 \pm 2 \cdot 19$ $\mathrm{mmol} / \mathrm{l}$, mean $\pm \mathrm{SD}$ upright) than the low salt diet (144.63 \pm 1.69 supine, $143.38 \pm 1.99$ $\mathrm{mmol} / \mathrm{l}$ upright). On the contrary, plasma potassium increments tended to be greater on the low sodium diet ( $3.11 \pm 0.63$ supine, $3.45 \pm 0.50 \mathrm{mmol} / 1$, mean \pm SD upright) than the high sodium diet $(2.95 \pm 0.56$ supine, $3.14 \pm 0.64 \mathrm{mmol} / \mathrm{l}$ upright $)$.

In subjects who remained supine for $4 \mathrm{~h}$ (groups $f$ and $g$ ), no systematic changes in plasma sodium or potassium or in serum potassium were seen (Table 1). Serum sodium, however (group $g$ ), fell by a mean of $1.4 \mathrm{mmol} / 1(P<0.05)$ by the third supine hour.

No evidence of haemoglobin, and hence no suggestion of haemolysis, was apparent in the six plasma samples obtained during head-up tilt and submitted to spectroscopy. 


\section{DISCUSSION}

We observed, by chance, that plasma sodium tended to fall and plasma potassium to rise in healthy subjects during head-up tilting. When care was taken with venepuncture and the subsequent processing of blood samples, this phenomenon was regularly seen.

These electrolyte changes occurred during both morning and afternoon testing, with or without prior fasting, whether serum or plasma was analysed, whether a standardized head-up tilt or quiet ambulation was utilized, with both an indwelling venous cannula and with separate venepunctures, and also when blood was drawn through a catheter in the superior vena cava. The only exception was the absence of fall in plasma sodium with head-up tilt when blood was obtained from the superior vena cava. Since particular attention was directed to the technique of venepuncture and handling of samples, and since haemoglobin was not detected in aliquots of plasma, haemolysis could not be invoked to explain the rise in potassium with upright posture. Our findings appear to reflect, therefore, a true in vivo change in electrolyte concentrations. Change to the upright posture appeared causative, because the circulating electrolyte concentrations returned toward baseline values in most instances with resumption of supine posture. Moreover, we did not see significant electrolyte fluctuations in subjects who remained supine for $4 \mathrm{~h}$ with the exception of a fall in serum, but not in plasma, sodium concentration.

A tendency for potassium levels to rise with upright posture has previously been reported in normal subjects (Rado et al., 1979; Sassard at al., 1976; Weidmann et al., 1975 ) and in patients with hyporeninaemic hypoaldosteronism (Rado et al., 1979), but in only one of these studies (Sassard et al., 1976) were techniques of blood withdrawal or sample handling detailed. In addition, we are not aware of data on posture-dependent changes in sodium concentration.

The mechanisms producing the observed changes in circulating potassium and sodium could well be multiple. Sassard et al. (1976) speculated that the rise in plasma potassium they observed on orthostasis might reflect a release of intracellular potassium from exercising muscles. This is certainly plausible, and a similar mechanism is probably responsible for the marked increase in plasma potassium which is found in blood drawn from an antecubital vein after forearm muscular exercise (Brown et al., 1970). Some muscular activity is needed to maintain the upright posture on head-up tilting on a tilt table. Another contributory factor could be an increase in circulating noradrenaline, a consistent accompaniment to upright tilting or orthostasis (Young et al., 1980). Ross (1960) observed that the intravenous infusion of noradrenaline $0 \cdot 2 \mu \mathrm{g} \cdot \mathrm{kg}^{-1} \cdot \mathrm{min}^{-1}$ into volunteers for 30 min caused a marked fall in plasma sodium with a rise in plasma potassium concentrations. He concluded that there must be active transfer of sodium ions from the extracellular to the intracellular compartment under the influence of noradrenaline.

Three major stimuli to aldosterone secretion are angiotensin II, corticotrophin and potassium, and these could well be reinforced by a fall in plasia sodium concentration (Davis, 1967; Fraser et al., 1979). There is evidence that all of these factors contribute, in varying extents, to the increase in plasma aldosterone on assumption of the upright posture (Sassard et al., 1976; Morganti et al.. 1979). It may be particularly relevant that aldosterone secretion can be stimulated by minor (Dluhy et al., 1977), even barely measurable increments in plasma potassium concentration (Birkhauser et al., 1973).

Of particular clinical relevance is our demonstration of a rise in potassium and a fall in 
sodium concentration during ambulation in patients with primary aldosteronism. We did not examine electrolyte levels in patients with primary aldosteronism during supine rest to rule out the possibility of a diurnal change in sodium and potassium in these subjects. However, other workers have looked at this point and report no change in potassium concentrations during recumbency (Schambelan et al., 1976; Wenting et al., 1978). Our findings in primary aldosteronism relate, therefore, to change in body posture rather to any inherent diurnal pattern, at least in the case of potassium. Schambelan et al. (1976) and Ganguly et al. (1973) previously reported small increments in plasma potassium during upright posture in primary aldosteronism, but details regarding handling of the blood samples were not given and statistical analyses were not made. In a number of our patients, supine electrolyte levels were marginally or distinctly abnormal, yet returned into or close to the normal range with ambulation. In individual instances (Fig. 1) serum potassium rose from 3.1 to 3.8 and from 2.4 to $3.1 \mathrm{mmol} / 1$. Thus, this standard diagnostic procedure, employed in many centres, tended to obscure the unique combination of hypokalaemia and hypernatraemia, which often provides the initial clue to the diagnosis of primary aldosteronism. It appears critical that, in the interpretation of plasma and serum electrolyte values, account is taken of whether the samples were drawn with the patient supine or after ambulation. A suspicion of primary aldosteronism should be entertained when even slight hypokalaemia and hypernatraemia are observed in an ambulant hypertensive patient.

\section{ACKNOWLEDGEMENTS}

We are grateful to Mary Elkins for assistance with statistical analysis and to Dr R. J. Grekin for permitting us to study his patients with primary aldosteronism. Studies at the University of Michigan received support from USPHS grant no. 5MO1-RR-42 to the Clinical Research Center. The studies of Dr Sonkodi and Dr Nicholls at the Western Infirmary, Glasgow, were performed respectively during the tenure of a British Council Scholarship and a Medical Research Council of New Zealand Travelling Scholarship. Additional support was provided by Astra Chemicals, Watford, UK.

\section{REFERENCES}

Birkhauser, M., Gaillard, R., Riondel, A.M., Scholer, D., Vallotton, M.B. \& Muller A.F. (1973) Effect of volume expansion by hyperosmolar and hyperoncotic solutions under constant infusion of angiotensin Il on plasma aldosterone in man and its counterbalance by potassium administration. European Journal of Clinical Investigation, 3, 307-316.

Brown, J.J., Chinn, R.H., Davies, D.L., Fraser, R., Lever, A.F., Rae, R.J. \& Robertson, J.I.S. (1970) Falsely high plasma potassium values in patients with hyperaldosteronism. British Medical Journal, ii, 18-20.

DANOWSKI, T.S. (1941) The transfer of potassium across the human blood cell membrane. Journal of Biological Chemistry, 139, 693-705.

DAvis, J.O. (1967) The regulation of aldosterone secretion. In The Adrenal Cortex (ed. A. B. Eisenstein), pp. 203-248. J. \& A. Churchill, London.

Dluhy, R.G., Greenfield, M. \& Williams, G.H. (1977) Effect of simultaneous potassium and saline loading on plasma aldosterone levels. Journal of Clinical Endocrinology and Metabolism, 45, 141-146.

Farber, S.J., Pellegrino, E.D., Conan, N.J.\& Earle, D.P. (1951) Observations on the plasma potassium level of man. American Journal of Medical Science, 221, 678-687.

Fraser, R., Brown J.J., Lever, A.F., Mason, P. \& Robertson, J.I.S. (1979) Control of aldosterone secretion. Clinical Science, 56, 389-396.

Ganguly, A., Melada, G.A., Luetscher, J.A. \& Dowdy, A.J. (1973) Control of plasma aldosterone in 
primary aldosteronism: distinction between adenoma and hyperplasia. Journal of Clinical Endocrinology and Metabolism, 37, 765-775.

Morganti, A., Sealey, J.E., Lopez-Ovejero, J.A., Pickering, T.G. \& Laragh J.H. (1979) The substitutive role of ACTH in supporting aldosterone response to head-up tilt during renin suppression in patients with essential hypertension. Hypertension, 1, 130-135.

Rado, J.P.. Simatupang. T., BoER, P. \& MEFs. E.J.D. (1979) Increase of serum potassium in the upright posture in selective hypoaldosteronism. Hormone and Metabolic Research, 11, 47-51.

Ross, E.J. (1960) Functional relationship between adrenal medullary and cortical hormones in man. Quarterly Journal of Medicine, 30, 285-295.

Sassard, J., Vincent, M.. Annat, G. \& Bizollan C.A. (1976) A kinetic study of plasma renin and aldosterone during changes of posture in man. Journal of Clinical Endocrinology and Metabolism, 42, 20-27.

Schambelan, M., Brust, N.L., Chang, B.C.F., Slater, K.L. \& Biglieri, E.G. (1976) Circadian rhythm and effect of posture on plasma aldosterone concentration in primary aldosteronism. Journal of Clinical Endocrinology and Metabolism, 43, 115-123.

Weidmann, P., de Myttenaere-Bursztein, S., Maxwel., M.H. \& de Lima, J. (1975) Effect of ageing on plasma renin and aldosterone in normal man. Kidney International, 8, 325-333.

Wenting, G.J., Man In't Veld, A.J., Derkx, F.H., Brummelen, P.V. \& Schalekamp, M.A.D.H. (1978) ACTH-dependent aldosterone excess due to adrenocortical adenoma: a variant of primary aldosteronism. Journal of Clininical Endocrinology and Metabolism, 46, 326-335.

Young, J.B., Rowe, J.W., Pallotta, J.A., Sparrow, D. \& Landsberg, L. (1980) Enhanced plasma norepinephrine response to upright posture and oral glucose administration in elderly human subjects. Metabolism, 29, 532-539. 